\title{
Platelet-derived growth factor isoform expression in carbon tetrachloride-induced chronic liver injury
}

\author{
Erawan Borkham-Kamphorst ${ }^{1}$, Evgenia Kovalenko ${ }^{1}$, Claudia RC van Roeyen², Nikolaus Gassler ${ }^{3}$, Michael Bomble ${ }^{1}$, \\ Tammo Ostendorf ${ }^{2}$, Jürgen Floege ${ }^{2}$, Axel M Gressner ${ }^{1}$ and Ralf Weiskirchen ${ }^{1}$
}

Platelet-derived growth factor (PDGF) has an essential role in liver fibrogenesis, as PDGF-B and -D both act as potent mitogens on culture-activated hepatic stellate cells (HSCs). Induction of PDGF receptor type- $\beta$ (PDGFR $\beta$ ) in HSC is well documented in single-dose carbon tetrachloride $\left(\mathrm{CCl}_{4}\right)$-induced acute liver injury. Of the newly discovered isoforms PDGF$C$ and $-D$, only PDGF-D shows significant upregulation in bile duct ligation (BDL) models. We have now investigated the expression of PDGF isoforms and receptors in chronic liver injury in vivo after long-term $\mathrm{CCl}_{4}$ treatment and demonstrated that isolated hepatocytes have the requisite PDGF signaling pathways, both in the naive state and when isolated from $\mathrm{CCl}_{4}$-treated rats. In vivo, PDGF gene expression showed upregulation of all PDGF isoforms and receptors, with values peaking at 4 weeks and decreasing to near basal levels by 8 and 12 weeks. Interestingly, PDGF-C increased significantly when compared to BDL-models. PDGF-A, PDGF-C and PDGF receptor type- $\alpha$ (PDGFR $\alpha$ ) correlated closely with in-

flammation and steatosis. Immunohistochemistry revealed expression of PDGF-B, $-C$ and $-D$ in areas corresponding to centrilobular necrosis, inflammation and fibrosis, whereas PDGF-A localized in regenerative hepatocytes. PDGFR $\beta$ was identified along the fibrotic septa, whereas PDGFR $\alpha$ showed positive staining in fibrotic septa and regenerative hepatocytes. Despite a significant decline of PDGF isoforms, hepatocyte regeneration peaked at 8 weeks. A marked difference in the degree of fibrosis was observed amongst the individual animals. In summary, PDGF expression in liver damage primarily parallels mesenchymal cell proliferation and extracellular matrix production, rather than hepatocyte regeneration. We conclude that PDGF levels in chronic liver injury peak at 4 weeks after onset of injury, and that the outcome of chronic toxic liver injury strongly depends on the individual capacity for tissue regeneration in the weeks following the peak of PDGF expression.

Laboratory Investigation (2008) 88, 1090-1100; doi:10.1038/labinvest.2008.71; published online 28 July 2008

KEYWORDS: PDGF; PDGFR; liver fibrosis; $\mathrm{CCl}_{4}$ rat model

Platelet-derived growth factor (PDGF), a family of growth factors composed of four different polypeptide chains is encoded by four different genes. The classical PDGFs (ie, PDGF-A and PDGF-B) undergo intracellular activation during transport in the exocytic pathway for subsequent secretion, whereas the novel PDGFs (ie, PDGF-C and PDGF-D) are secreted as latent forms that require activation by extracellular proteases. These PDGF isoforms act by two receptor tyrosine kinases, PDGF receptors- $\alpha$ and $-\beta$ (PDGFR $\alpha$ and $-\beta$ ) that require PDGF-mediated dimerization for ligand binding and signaling. PDGF-A binds and signals through PDGFR $\alpha$ only, whereas PDGF-B binds both PDGFR $\alpha$ and $-\beta$ in all three possible combinations $(\alpha \alpha, \alpha \beta$ and $-\beta \beta)$. Activated
PDGF-C binds to both PDGFR $\alpha \alpha$ and $-\alpha \beta$, but PDGF-D is a known PDGFR $\beta$-specific ligand. PDGF-A and PDGF-B regulate various physiological and pathophysiological processes, mainly targeting cells of mesenchymal origin (reviewed in Fredriksson et $a l^{1}$ ).

In liver fibrogenesis, PDGF-B and -D isoforms act as potent mitogens in culture-activated hepatic stellate cells (HSC). ${ }^{2,3}$ Induction of PDGF-B and PDGFR $\beta$ in HSC is well documented in single-dose carbon tetrachloride $\left(\mathrm{CCl}_{4}\right)_{-}$ induced acute liver injury and during early stages of bile duct ligation (BDL). ${ }^{4,5}$ Of the newly discovered isoforms, PDGF-C and -D, only PDGF-D showed significant upregulation in the BDL rat model. ${ }^{3}$ Previous experiments using the $\mathrm{CCl}_{4}$ model

\footnotetext{
Institute of Clinical Chemistry and Pathobiochemistry, RWTH-University Hospital Aachen, Aachen, Germany; ${ }^{2}$ Division of Nephrology, RWTH-University Hospital Aachen, Aachen, Germany and ${ }^{3}$ Institute of Pathology, RWTH-University Hospital Aachen, Aachen, Germany Correspondence: Professor R Weiskirchen, Institute of Clinical Chemistry and Pathobiochemistry, RWTH-University Hospital, D-52074 Aachen, Germany. E-mail: rweiskirchen@ukaachen.de 
were confined to a period of 1-2 weeks and mainly represented single-dose $\mathrm{CCl}_{4}$ applications. Therefore, we investigated the expression of PDGF isoforms and their receptors in chronic liver injury induced by long-term repeated dosing of $\mathrm{CCl}_{4}$ in rats.

$\mathrm{CCl}_{4}$-induced liver fibrosis and cirrhosis is an established potent hepatotoxin-based experimental model with regard to characterization of histological and biochemical changes during injury, inflammation and fibrosis. The effects of $\mathrm{CCl}_{4}$ on hepatocytes are manifested as hepatic steatosis, hepatocellular necrosis, apoptosis, fibrosis and carcinoma. The toxic mechanism of $\mathrm{CCl}_{4}$ is believed to be the bioactivation of $\mathrm{CCl}_{4}$ to trichloromethyl-free radical $\left(\mathrm{CCl}_{3} *\right)$ by cytochrome $\mathrm{P} 450$ enzymes, primarily CYP2E1 in the endoplasmic reticulum. Subsequent adduct formation between $\mathrm{CCl}_{3}{ }^{*}$ and cellular molecules and formation of the highly reactive form of the trichloromethylperoxy radical $\left(\mathrm{CCl}_{3} \mathrm{OO} *\right)$ through reaction with oxygen is believed to initiate chain reactions that culminate in $\mathrm{CCl}_{4}$-induced toxicity. ${ }^{6}$

In this study, we demonstrate that the hepatic expression of all PDGF isoforms and receptors at both mRNA and protein levels increased in rats that repeatedly received the hepatotoxin. The values peaked at 4 weeks and decreased thereafter to near basal levels after 8 and 12 weeks.

\section{MATERIALS AND METHODS}

\section{Experimental In Vivo Liver Fibrogenetic Model}

Male Sprague-Dawley rats (6- to 8-week old) weighing 180$200 \mathrm{~g}$ were utilized for this study. A total of 30 rats received intraperitoneal injections twice weekly of $1 \mathrm{ml} / \mathrm{kg}$ of $\mathrm{CCl}_{4}$ in an equal volume of mineral oil for up to 12 weeks, whereas mineral oil alone was used for 12 control animals following established protocols. ${ }^{7}$ Groups of seven rats (five animals that received $\mathrm{CCl}_{4}$, two control animals) were killed $48 \mathrm{~h}$ after the last injection at time points of $48 \mathrm{~h}, 1,2,4,8$ and 12 weeks, respectively. Liver specimens were harvested and fixed in $4 \%$ paraformaldehyde for histological examination or snap frozen and stored at $-80^{\circ} \mathrm{C}$ for protein and RNA isolation. Liver function tests were performed according to standard protocols. This experiment was approved by the local review board according to prevailing guidelines for scientific animal experimentation.

\section{RNA Isolation and RT-PCR}

Liver RNA was isolated by guanidine thiocyanate/CsCl method, followed by DNAase digestion. Total RNA $(2 \mu \mathrm{g})$ was reverse transcribed in $20-\mu \mathrm{l}$ volume using Superscript II reverse transcriptase (Invitrogen) and random hexamer primers. For integrity verification, $2-\mu \mathrm{l}$ aliquots of cDNA samples were subjected to standard PCR for ribosomal protein S6 (RPS6).

\section{Real-Time Quantitative PCR}

The cDNA derived from 25 ng RNA was amplified in $25-\mu \mathrm{l}$ volume using qPCR Core Kits (Eurogentec). PCR conditions were set to $50^{\circ} \mathrm{C}$ for $2 \mathrm{~min}, 40$ cycles of $95^{\circ} \mathrm{C}$ for $15 \mathrm{~s}$ and $60^{\circ} \mathrm{C}$ for $1 \mathrm{~min}$. TaqMan primers and probes for amplification of the different PDGF isoforms and receptors ${ }^{3}$ were designed from sequences deposited in the GenBank database using the Primer Express software (Applied Biosystems). As an internal control, an rRNA fragment was amplified using the TaqMan Ribosomal RNA Control Reagents (Applied Biosystems).

\section{SDS-PAGE and Immunoblotting}

Whole-cell and liver lysates were prepared as previously described. ${ }^{8}$ Equal amounts of proteins were resolved in NuPAGE $^{\mathrm{TM}}$ Bis-Tris gels (Novex) and electroblotted onto a Protran membrane (Schleicher \& Schuell). The following primary antibodies were employed: $\alpha$-smooth muscle actin $(\alpha$-SMA, clone asm-1; Cymbos Biotech), $\beta$-actin (A5441; Sigma), collagen type I (PS065; Monosan), PDGF-A (AF1055) from R\&D Systems, rat fibronectin (AB1954; Chandlers Ford Hampshire), PDGFR $\alpha$ (sc-338) and PDGFR $\beta$ (sc-432), c-Met (B-2, sc-8057) (Santa Cruz), phosphoPDGFR $\alpha$ (Y754, no. 2992), phospho-Akt (pS473, no. 40518), total Akt (no. 9272), phospho-p44/p42 (ERK1/2) (pT202/ pY204, no. 9101), p44/42 (no. 9102), phospho-c-Met (pTyr1234/1235, no. 3129) and S6 ribosomal protein (no. 2317) from Cell Signaling, monoclonal phospho-tyrosine (clone 4G10, 05-321; Upstate Biotechnology). Primary antibodies were visualized using horseradish peroxidaseconjugated anti-mouse-, anti-rabbit- or anti-goat IgG (Santa Cruz) and the SuperSignal chemiluminescent substrate (Pierce).

For generation of whole-cell lysates, freshly isolated or cultured hepatocytes were washed in ice-cold PBS and solubilized in lysis buffer containing $50 \mathrm{mM}$ Tris- $\mathrm{HCl}$ ( $\mathrm{pH} 6.8), 250 \mathrm{mM} \mathrm{NaCl}, 2 \%(\mathrm{v} / \mathrm{v})$ NP40, $2.5 \mathrm{mM}$ EDTA, $0.1 \%(\mathrm{w} / \mathrm{v})$ SDS, $0.5 \%(\mathrm{w} / \mathrm{v})$ sodium deoxycholate and a protease inhibitor cocktail (Roche Diagnostics) and a phosphatase inhibitor (Sigma) that were added before use. Whole-cell lysates were sonicated and centrifuged at 10000 r.p.m. at $4^{\circ} \mathrm{C}$ for $10 \mathrm{~min}$, supernatants collected, quantified using Bio-Rad DC Protein Assay, subjected to SDS-PAGE and immunoblotted for protein detection.

\section{Immunohistochemistry of Liver Sections}

Liver tissue sections were deparaffinized and rehydrated with xylene and decreasing graded ethanol, whereas antigen retrieval was engendered by heating the sections in $0.01 \mathrm{M}$ sodium citrate buffer ( $\mathrm{pH} \mathrm{6)}$ in a microwave for $20 \mathrm{~min}$. Slides were blocked for nonspecific binding with $10 \%$ serum of the species of which the second antibody was made in $1 \%$ BSA, $0.1 \%$ cold fish skin gelatin, $0.1 \%$ Triton $\mathrm{X}-100$ and $0.05 \%$ Tween 20 , followed by avidin-biotin and peroxidase blocking solution (DAKO). Detection of PDGF isoforms and their receptors was achieved through goat anti-PDGF-A (AF1055), rabbit anti-PDGF-B (Abcam), goat anti-mouse PDGF-C (AF1447; R\&D Systems) and rabbit anti-human 
PDGF-D (40-2100) (Zymed Laboratories), polyclonal rabbit anti-PDGFR $\alpha$ (sc-338), and anti-PDGFR $\beta$ (sc-432). Other antibodies were against the proliferating cell nuclear antigen (PCNA) (sc-56), ED2 (CD163; Serotec), and TIMP-1 (AF580; R\&D systems). Primary antibodies were diluted in $1 \%$ BSA in PBS to concentrations of $2-5 \mu \mathrm{g} / \mathrm{ml}$ and incubated at $4^{\circ} \mathrm{C}$ overnight, while an immunoglobulin $(\operatorname{IgG})$ was used for negative control. Sections were incubated with biotinylated secondary antibodies (BA-9200, Vector Laboratories), followed by avidin-conjugated peroxidase (Vectastain ABC-Elite reagent, Vector Laboratories) and 3,3'-diaminobenzidine substrate (DAKO). For staining of PDGF-B, PDGF-C, and PDGF-D, we used an alkaline phosphatase anti-alkaline phosphatase (APAAP) protocol using a mouse monoclonal antibody (D0651) and the Fast Red substrate (both from DAKO). The sections were briefly counterstained with hematoxylin.

\section{PCNA and TUNEL Staining of Liver Sections}

PCNA, an auxiliary protein of DNA polymerase delta is essential for DNA replication in eukaryotic cells. Its expression is cell cycle dependent, being first detectable in late $G_{1}$ and maximizes in $S$ phase. Immunohistochemical techniques were used to demonstrate PCNA in hepatocytes. $G_{0}$ cells stain blue and did not take PCNA stain, cells in $\mathrm{G}_{1}$ are light brown, $S$-phase cell nuclei stain dark brown, while cell in $\mathrm{G}_{2}$ phase have a cytoplasmic stain with or without speckle nuclear appearance. For quantification, tissue sections were inspected at $400 \times$ magnification and the labeled nuclei counted in 10 randomly chosen fields with approximately 1000 cells per section.

Terminal deoxynucleotidyl transferase (TdT)-mediated dUTP-biotin nick end labeling (TUNEL) was performed with an in situ cell death detection kit (Roche Diagnostics) according to the manufacturer's instructions. Deparaffinized tissue sections were rehydrated and permeabilized in heated $0.1 \mathrm{M}$ sodium citrate buffer $(\mathrm{pH} 6)$ applying $350 \mathrm{~W}$ in a microwave for $5 \mathrm{~min}$. The sections were then incubated for $1 \mathrm{~h}$ at $37^{\circ} \mathrm{C}$ with TUNEL reaction mixture containing terminal $\mathrm{TdT}$ to catalyze polymerization of fluorescein-labeled nucleotides to free $3^{\prime}$-OH DNA strand break. Apoptotic cells were detected by fluorescence microscopy. Incubation of the sections with DNase I before TUNEL reaction served as positive control while omitting $\mathrm{TdT}$ as negative control.

\section{Cell Isolation and Culture}

Primary hepatocytes were isolated from livers of male SpragueDawley rats $(200 \mathrm{~g})$ with two-step collagenase perfusion method, adapted from the original procedure of Seglen. ${ }^{9,10}$ Cells were plated on collagen-coated plates at a density of $7-10 \times 10^{4}$ cells per $\mathrm{cm}^{2}$ in HepatoZYME-SFM (Gibco Invitrogen) supplemented with $2 \mathrm{mM} \mathrm{L}$-glutamine and $1 \%$ penicillin/streptomycin. Cells were then incubated in 5\% $\mathrm{CO}_{2}$ at $37^{\circ} \mathrm{C}$ to facilitate attachment, and the medium renewed after $1 \mathrm{~h}$. The next day, cells were starved in serum-free
DMEM for $24 \mathrm{~h}$ and the medium changed to $0.1 \%$ BSA in DMEM for $1 \mathrm{~h}$. Hepatocytes were stimulated with PDGF isoforms $(25-50 \mathrm{ng} / \mathrm{ml})$, hepatocyte growth factor (HGF) $(20 \mathrm{ng} / \mathrm{ml})$, epidermal growth factor (EGF) $(10 \mathrm{ng} / \mathrm{ml})$ or $10 \%$ fetal calf serum (FCS) for $15 \mathrm{~min}$ at $37^{\circ} \mathrm{C}$, washed and harvested for SDS-PAGE and immunoblot.

\section{Hepatocyte BrdU Incorporation Assay}

Primary hepatocytes were plated at 250000 cells per well in 12-well collagen-coated cultured plates using HepatoZYMESFM. After $1 \mathrm{~h}$ the medium was renewed and cells were incubated with PDGF isoforms $(25-50 \mathrm{ng} / \mathrm{ml})$ or $10 \%$ FCS. Cells were labeled with $10 \mu \mathrm{M}$ 5-bromo-2'-deoxyuridine (BrdU) for $24 \mathrm{~h}$ using the Cell ELISA BrdU colorimetric assay kit (Roche Diagnostics). Upon culture medium removal, cells were fixed and DNA denatured in one step by adding FixDenat ( $400 \mu \mathrm{l}$ per well) for $1 \mathrm{~h}$ at RT, followed by incubation with an anti-BrdU antibody conjugated to peroxidase (antiBrdU-POD, $400 \mu \mathrm{l}$ per well) for $2 \mathrm{~h}$. This antibody binds to BrdU incorporated into the newly synthesized DNA. After threefold washing, bound anti-BrdU-POD were detected by a substrate reaction $(600 \mu \mathrm{l})$ for $10-30 \mathrm{~min}$, the reaction was interrupted with $1 \mathrm{M} \mathrm{H}_{2} \mathrm{SO}_{4}(300 \mu \mathrm{l})$ and quantified in an ELISA plate reader at $450 \mathrm{~nm}$.

\section{Statistical Analysis}

The statistical analyses were performed using the KruskalWallis test for nonparametric multiple comparison with a statistical software program (STATGRAPHICS Plus, version 5.1). Results are expressed by the median values followed by range. Probability values of less than 0.05 were considered statistically significant. To establish the differences within the control group we used a Mann-Whitney-Wilcoxon test.

\section{RESULTS \\ Responsiveness of Hepatocytes to PDGF Isoforms In Vitro}

To analyze PDGF signaling in hepatocytes, 1-day primary cultures were serum-starved for $24 \mathrm{~h}$ and stimulated with PDGF isoforms (25-50 ng/ml), HGF (20 ng/ml), EGF (10 ng/ $\mathrm{ml}$ ) or $10 \%$ FCS for $15 \mathrm{~min}$ at $37^{\circ} \mathrm{C}$. PDGF signaling pathways were evaluated by detection of Tyr residue autophosphorylation of PDGF-activated PDGFR, phosphorylation of ERK1/2 of MAPK and Akt of PI3K. Only the PDGF isoforms $B$ and D evoked marginal effects on phospho-Tyr of PDGFR. However, all isoforms significantly triggered phosphorylation of ERK1/2 that was comparable to those obtained by stimulation with HGF or EGF. Further, PDGF-B, PDGF-D and HGF slightly increased phosphorylation of Akt, whereas HGF induced c-Met phosphorylation (Figure 1a). These findings were similar to those obtained in the hepatocellular carcinoma (HSC) cell line Hep3B (Supplementary Figure 1). All PDGF isoforms and 10\% FCS induced significant hepatocyte proliferation as evidenced in BrdU incorporation assay (Figure 1b). 

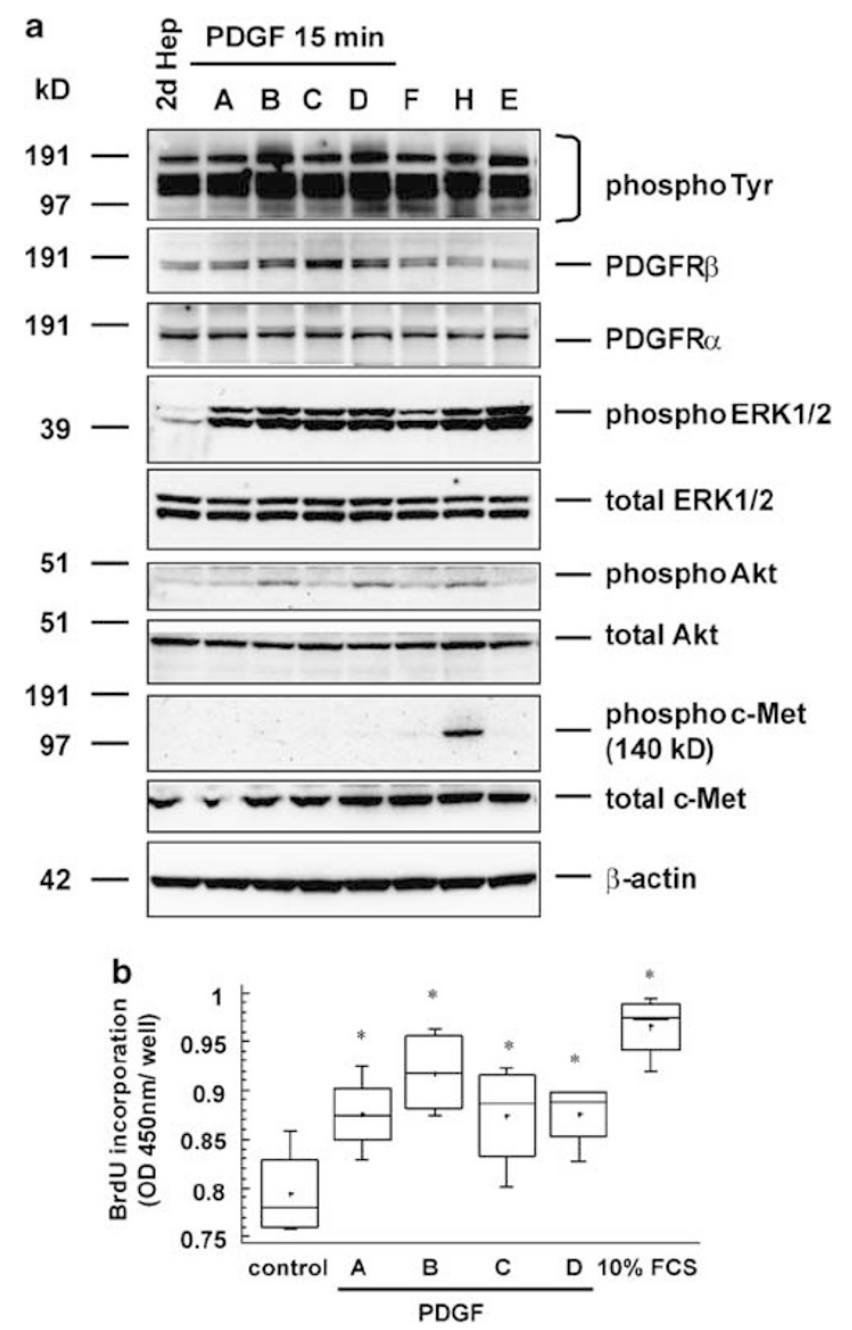

Figure 1 PDGF signaling and BrdU incorporation assay in cultured hepatocytes. (a) Two-dimensional cultured hepatocytes were starved in serum-free DMEM for $24 \mathrm{~h}$ and subsequently stimulated with PDGF-A (A), -B (B), -C (C), or -D (D), 10\% FCS (F), HGF (H), or EGF (E). All PDGF isoforms significantly induced ERK $1 / 2$ phosphorylation that was comparable to those obtained after stimulation with $10 \%$ FCS, HGF, or EGF. PDGF-B and -D showed increased PDGFR Tyr phosphorylation. Furthermore, PDGF-B, -D, and HGF induced slight activation of Akt. To confirm the specificity of HGF signaling, the phosphorylation of c-Met was analyzed. (b) Primary hepatocytes were subjected to proliferation assay as outlined in 'Materials and methods'. All PDGF isoforms induced significant hepatocytes proliferation, whereas $10 \%$ FCS showed the strongest effect. The box and whisker plots diagram contains the statistical median as a horizontal line; the upper edge of the box indicates the 75th percentile of the data set, the lower indicates the 25th percentile. The crosses in the box represent the mean and statistically significant values $(P<0.05)$ are marked by asterisks. The plots depict the results of three independent experiments.

Immunoblot of PDGF Isoforms and Receptors in Primary Hepatocytes Isolated from $\mathrm{CCl}_{4}$-Treated Rats

Isolated hepatocytes from $\mathrm{CCl}_{4}$-treated rats exhibited increased PDGFR $\alpha$ expression that declined after culturing in HepatoZYME-SFM medium, whereas the expression of PDGF-A increased upon continued culturing (Figure 2). The observed expression kinetic was similar to that described for connective tissue growth factor. ${ }^{11}$ PDGFR $\beta$ was only moderately expressed, whereas the other PDGF isoforms could not be detected (not shown). Surprisingly, in contrast to our in vivo findings, cultured primary hepatocytes showed significant expression of fibronectin (compare Figure 2 and Supplementary Figure 2).

\section{PDGF Isoform and Receptor mRNA Expressions in Chronic $\mathrm{CCl}_{4}$-Treated Rat Livers}

Relative mRNA levels of all PDGF isoforms in rat liver increased significantly $(P<0.05)$ upon repeated $\mathrm{CCl}_{4}$ administration (Figure 3) (for detailed statistics see Supplementary Table 1). Values peaked at 2-4 weeks, decreasing thereafter to near basal levels at 8 weeks. At 12 weeks PDGF-B, -C, -D and PDGFR $\alpha$ showed a slight, but significant upward trend again. PDGFR $\alpha$ and $-\beta$ levels increased markedly, up to 10 -fold, after $1 \times \mathrm{CCl}_{4}$ administration, and these high levels were maintained for 4 weeks. PDGF-C increased significantly to 5.2- and 7.0-fold at 2 and 4 weeks, respectively $(P=0.019$ and $P=0.019$ ), this contrary to results reported for the BDL model. $^{3}$

\section{Immunohistochemistry of PDGF Isoforms and Their Receptors}

PDGF-A staining was found in regenerative hepatocytes, peripheral to the area of centrilobular hepatic necrosteatosis and in bile duct epithelia (Figure 4a). PDGFR $\alpha$ was detected in both vascular endothelial cells and regenerative hepatocytes of cirrhotic livers (Figure 4b). PDGFR $\beta$ localized in myofibroblasts along the fibrotic septa between the centrilobular bridging (Figure 4c). PDGF-B, -C and -D were found exclusively in the centrilobular areas (Figure $4 \mathrm{~d}$ ). In contrast to PDGFR $\beta$, PDGF-B staining was found in correspondence with ED2-positive inflammatory cells (Supplementary Figure 3). PDGF-C was detected in inflammatory cells and hepatocytes around central veins. PDGF-D staining was noted in bile duct epithelia and some periportal myofibroblasts. The expression of PDGF isoforms and receptors declined after 8 weeks of continued $\mathrm{CCl}_{4}$ administration.

\section{Fibrotic Effects of Chronic $\mathbf{C C l}_{\mathbf{4}}$ Administrations}

Rats receiving $\mathrm{CCl}_{4} 1 \mathrm{ml} / \mathrm{kg}$ twice weekly showed typical features of centrilobular liver damage, evidenced by prominent steatosis of hepatocytes at 1-4 weeks, and subsequent development of centrilobular bridging fibrosis. Grading of the levels of fibrosis was based on the Ishak fibrosis score with six stages, considered to be the most sensitive. ${ }^{12,13}$ In our analysis, fibrotic levels differed notably between the different animals (Supplementary Figure 4, Figure 5a, Supplementary Table 2). At week 8 , one rat (20\% of the group) died of uncompensated liver cirrhosis. Typical marker proteins reflecting ongoing fibrogenesis (eg, $\alpha$-SMA, fibronectin, TIMP-1) were expressed in the injured livers (Figure $5 b$ ).

PDGFR $\beta$ increased significantly upon the first dose of $\mathrm{CCl}_{4}$ administration, and levels were sustained until 4 weeks, 


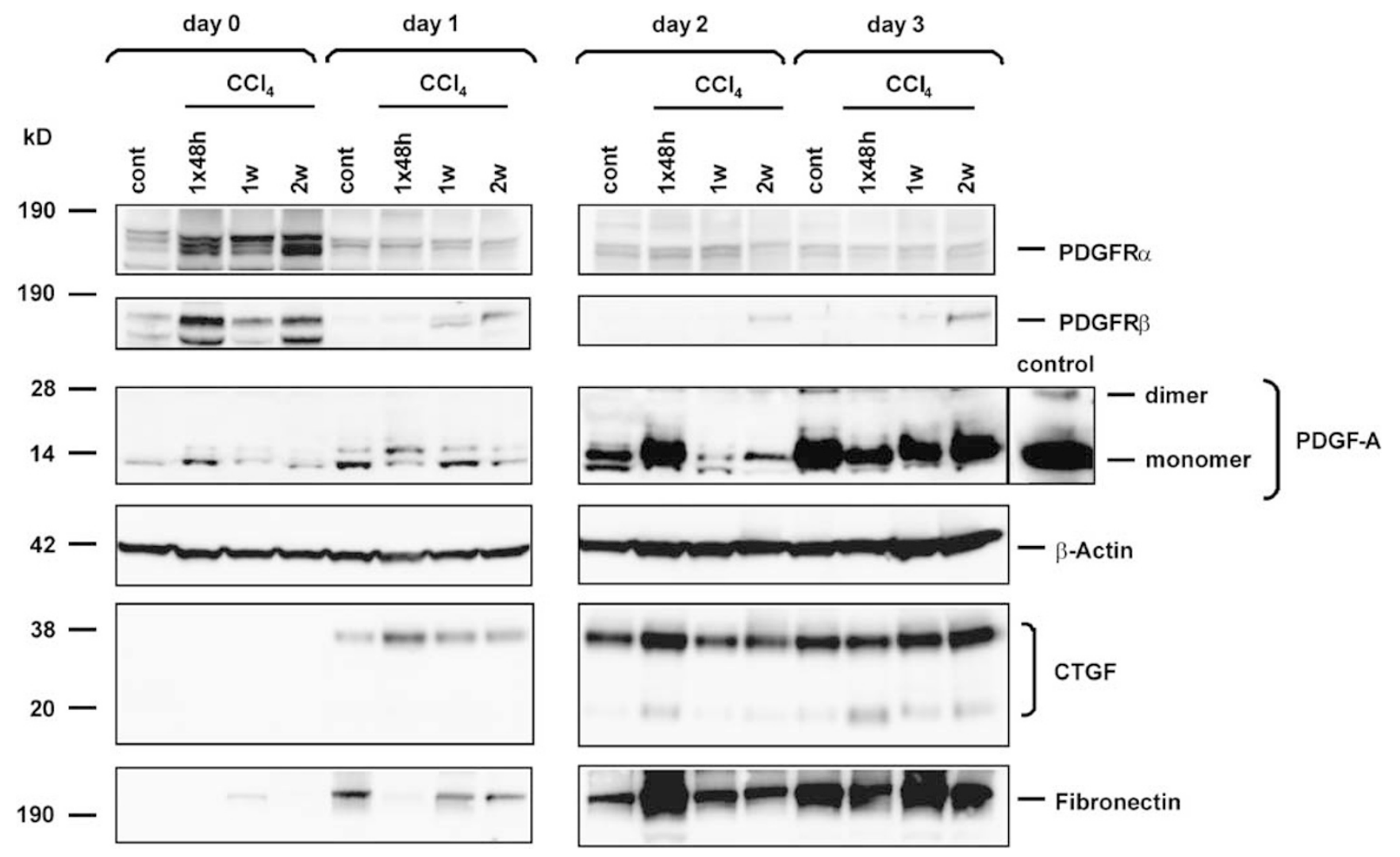

Figure 2 Western blot analysis of protein extracts taken from hepatocytes of $\mathrm{CCl}_{4}$-treated rats. Hepatocytes were isolated from rats that were subjected to $\mathrm{CCl}_{4}$ for indicated times. Protein extracts were prepared after different culture times and the expression of PDGFR $\alpha, \mathrm{PDGFR} \beta$, PDGF-A, $\beta$-actin, CTGF and fibronectin was analyzed by Western blot. The immunoblot showed increased PDGFR $\alpha$ expression in freshly isolated hepatocytes from $\mathrm{CCl}_{4}$-treated rats that declined upon continued culturing. The expression of PDGF-A, CTGF and fibronectin increased significantly during prolonged culturing, whereas PDGFR $\beta$ was only modestly detectable. In this analysis, the expression of $\beta$-actin was taken as a loading control.

corresponding closely to the mRNA levels. Fibronectin, predominantly produced by sinusoidal endothelial cells, was increased during early stage injury response. Surprisingly, the most severe cirrhotic rat showed no fibronectin expression at 12 weeks (cf Figure 5a, right lane). This might be due to the deformed anatomy and obliterated sinusoid. Fibronectin has been shown to stimulate the conversion of resting stellate cells to myofibroblast-like cells, consistent with the role of fibronectin in fibrogenesis and wound repair initiation. ${ }^{14}$ Collagen type I and $\alpha$-smooth muscle actin ( $\alpha$-SMA) were upregulated and levels sustained throughout $\mathrm{CCl}_{4}$ administration, with the exception of a few animals that showed a decline of $\alpha$-SMA, in correspondence with a lesser degree of fibrosis, confirmed by immunohistochemistry (Supplementary Figure 5). As expected, representative liver sections taken from animals that received long-term $\mathrm{CCl}_{4}$ exposure showed reactive chromatin condensation of hepatocyte nuclei (Supplementary Figure 6). However, in none of the livers we observed morphological evidence for hepatocyte hyperplasia or dysplasia, especially morphological features of nodular regenerative hyperplasia were not found.

Serum levels of aspartate and alanine aminotransferase, $\gamma$-glutamyltransferase and bilirubin increased upon $\mathrm{CCl}_{4}$ administration but normalized at 12 weeks (Supplementary Figure 7), whereas the serum levels of alkaline phosphatase and albumin remained unchanged.

\section{PCNA and TUNEL Staining}

Sublethal doses (up to $2 \mathrm{ml} / \mathrm{kg}$ ) of $\mathrm{CCl}_{4}$ are known to stimulate hepatocyte regeneration in a dose-dependent manner. ${ }^{15}$ Kinetic staining for the PCNA showed increased hepatocyte regeneration throughout the course of $\mathrm{CCl}_{4}$ application, peaking at 8 weeks despite a significant decline of PDGF isoforms and their receptors (Figure 6a and b). Interestingly, animals with higher extends of fibrosis showed lower PCNA levels than less fibrotic animals (Figure 6c).

Severe $\mathrm{CCl}_{4}$-induced acute hepatocellular damage was observed during the phase of hepatocyte apoptosis at 1 week, resulting in further recruitment of inflammatory cells and resident macrophages (ie, Kupffer cells) to the centrilobular area as evidenced in a strong positivity for ED2, a macrophage-specific marker, at 2 weeks (not shown).

\section{DISCUSSION}

Besides transforming growth factor- $\beta$ (TGF- $\beta$ ), PDGF is considered the second fibrotic cytokine in liver fibrogenesis. 
PDGF-A

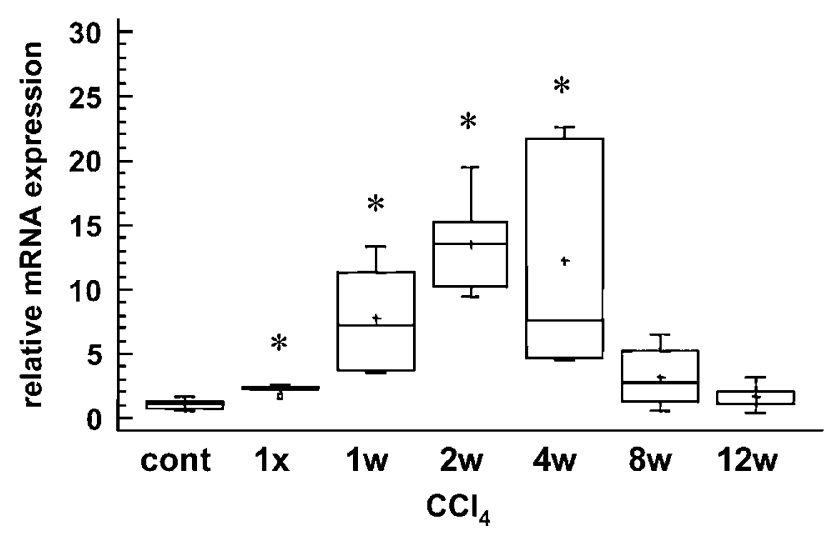

PDGF-C

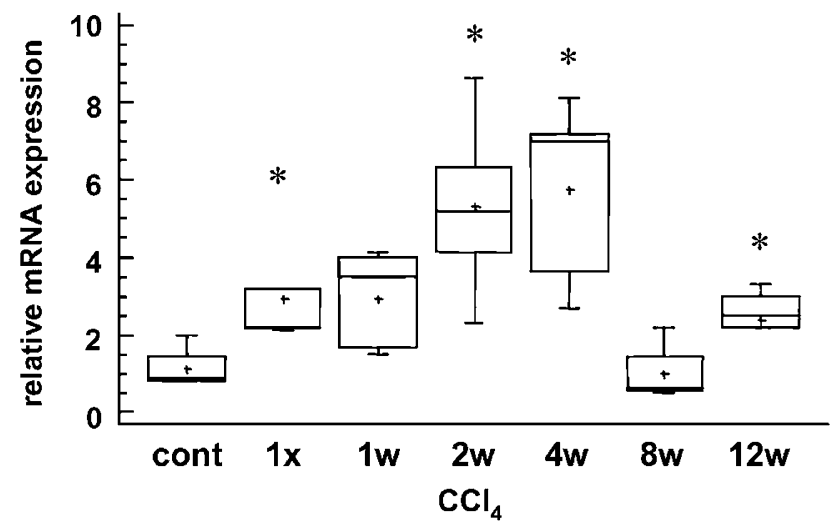

PDGFR $\alpha$

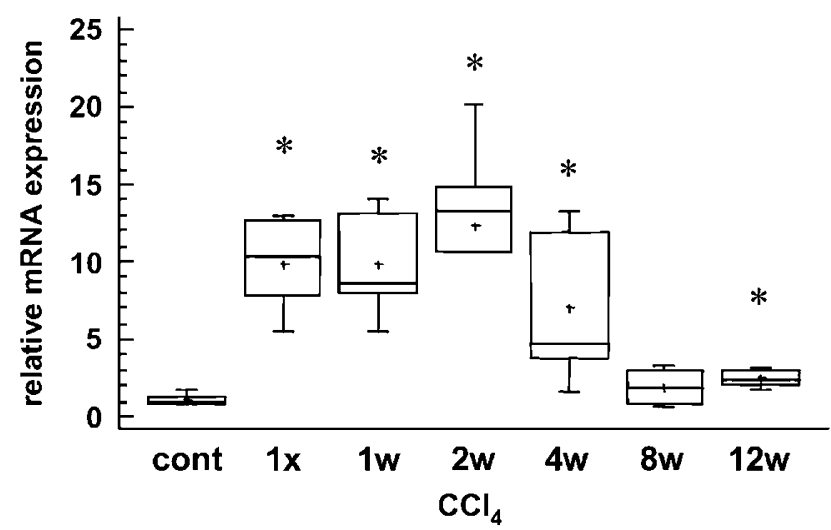

PDGF-B

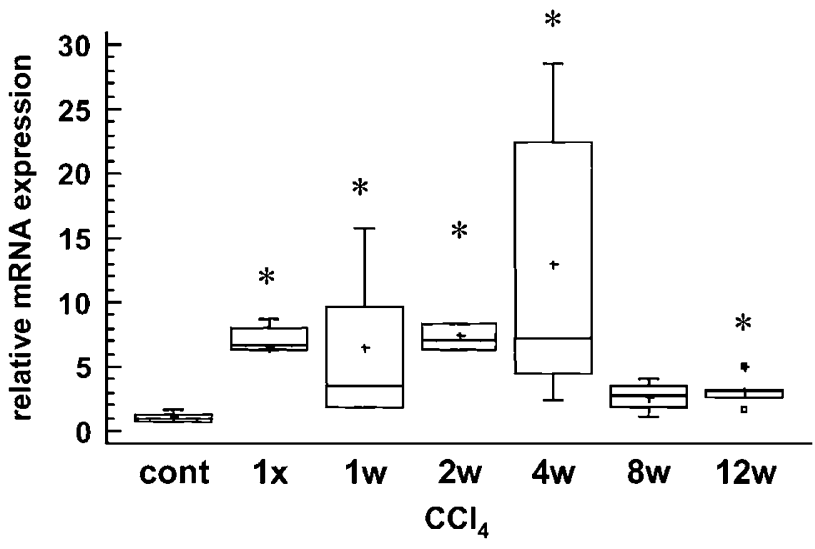

PDGF-D

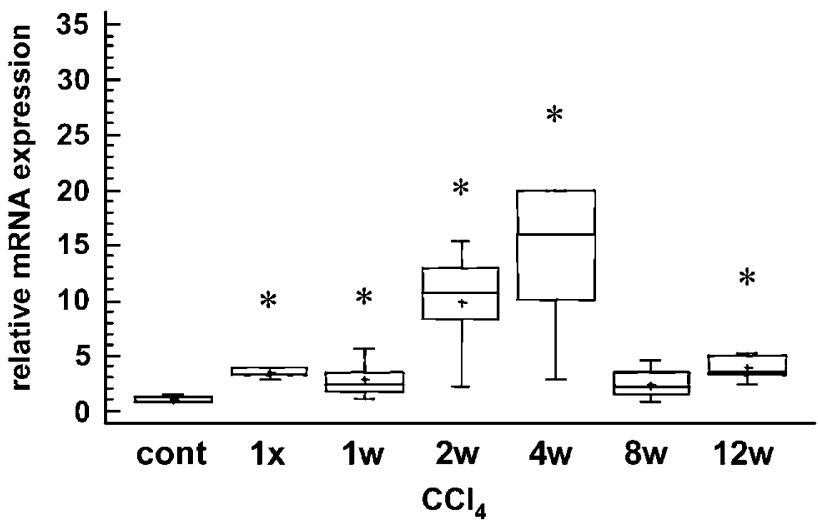

PDGFR $\beta$

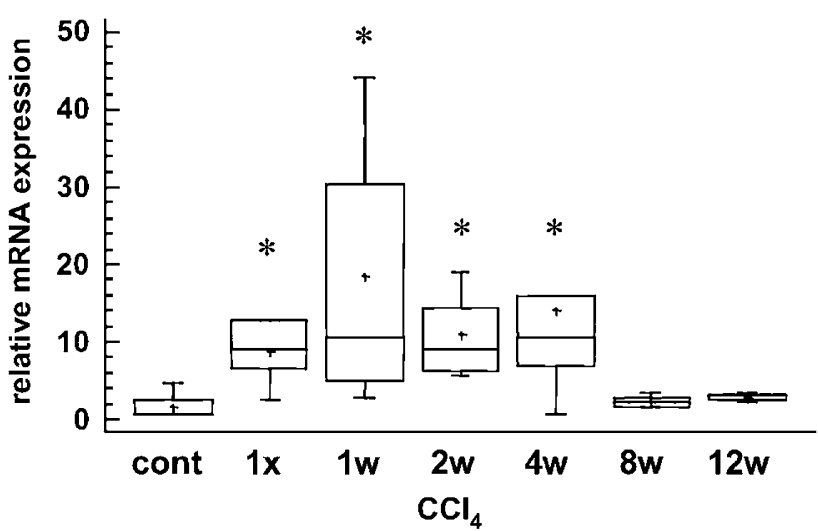

Figure 3 Relative mRNA expression of PDGF isoforms and receptors in chronic $\mathrm{CCl}_{4}$-treated rat livers. The expression of the different PDGF isoforms and their receptor was analyzed by quantitative real-time PCR (TaqMan). The analysis revealed that the relative mRNA levels of all PDGF isoforms and receptors

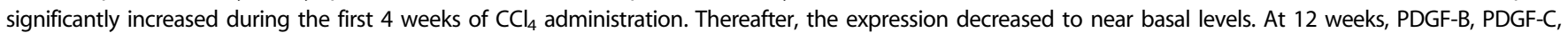
PDGF-D and PDGFR $\alpha$ showed a slight increasing trend again. The box and whisker plot depicts the mean values as dots and the median as a bar in each group $(n=5)$. Significant changes are marked by asterisks. For a detailed statistical analysis of these data see Supplementary Table 1.

Expression of PDGF isoforms in a BDL rat model is known to induce liver fibrosis without severe inflammation. ${ }^{16,17}$ To further elucidate the role of PDGF isoforms in liver fibrogenesis, we studied a $\mathrm{CCl}_{4}$-induced liver fibrosis rat model associated with severe inflammation and necrosis.
Chronic nonlethal dosing of $\mathrm{CCl}_{4}$ led to enhanced gene expression of all PDGF isoforms and their receptors with values generally peaking at 4 weeks. Surprisingly, the expression decreased to near basal levels at 8 and 12 weeks, despite continued $\mathrm{CCl}_{4}$ administration and the development of liver 
fibrosis. This extends a previous study ${ }^{18}$ on TGF- $\beta$ gene expression in chronic $\mathrm{CCl}_{4}$ intoxication at 1, 2, 3 and 7 weeks, showing increased TGF- $\beta$ mRNA expression in nonparenchymal cells only after 2 and 3 weeks of treatment. Our findings also coincide with data showing a significant increase in mRNA levels of tumor necrosis factor- $\alpha$ (TNF- $\alpha$ ), TGF- $\beta$, interleukin-6 (IL-6) a

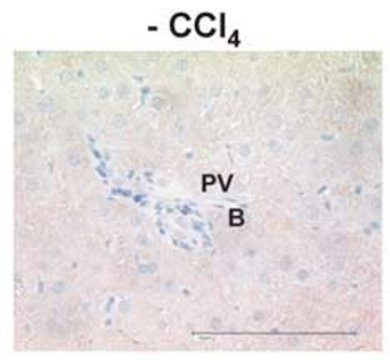

b

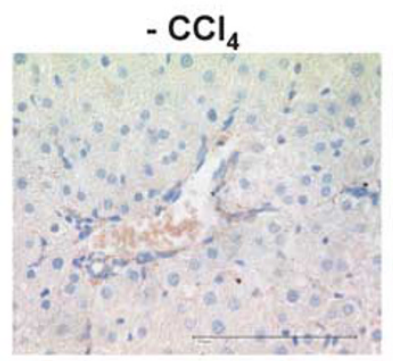

c

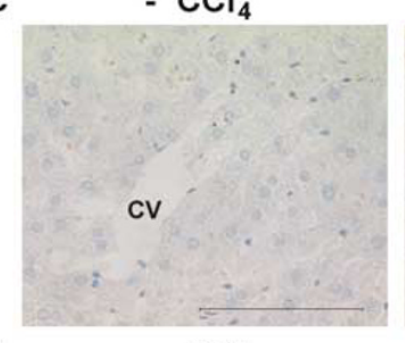

d
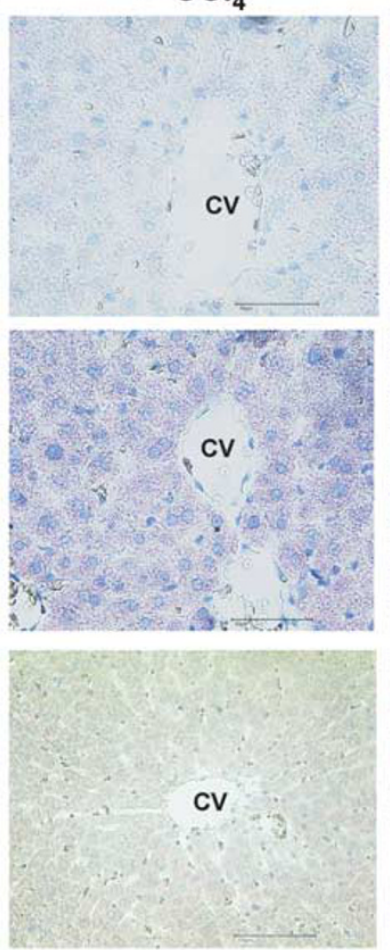

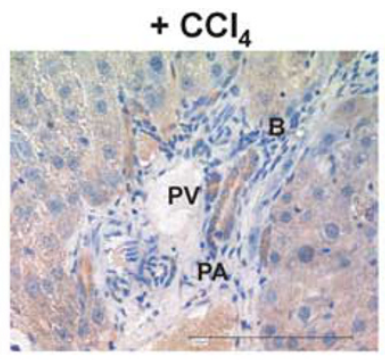

$+\mathrm{CCl}_{4}$
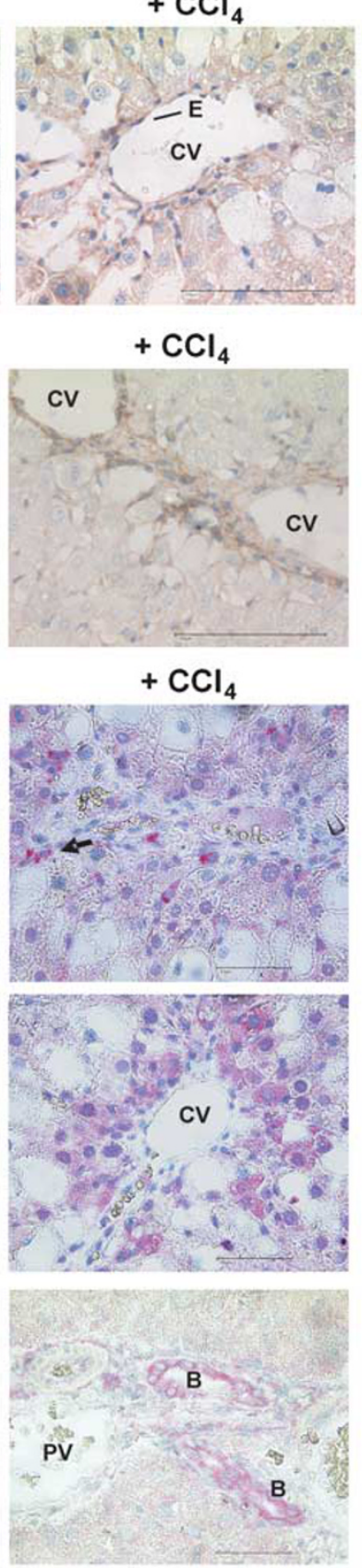

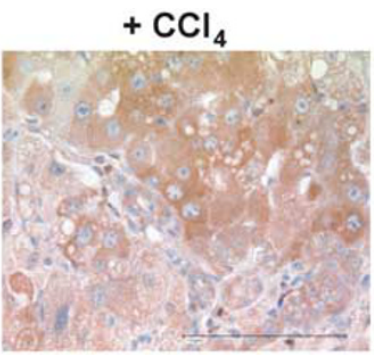

PDGF-A

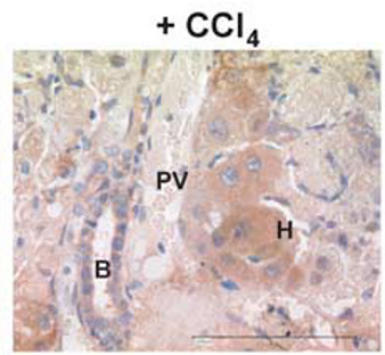

PDGFR $\beta$

PDGF-B

PDGF-C
PDGFR $\alpha$ 
and IL-1 $\beta$ in Kupffer cells isolated from $\mathrm{CCl}_{4}$-treated rats after 2 and 4 weeks, but with a return to normal levels at 6 weeks. ${ }^{19}$

In $\mathrm{CCl}_{4}$-induced liver injury, early infiltration by mononuclear cells is followed by proliferation of mesenchymal cells. Interplay between cytokines produced by the recruited inflammatory cells and especially activated Kupffer cells at the sites of $\mathrm{CCl}_{4}$ injury is believed to trigger a cascade of reactions leading to fibrotic responses, culminating in development of fibrotic septa, and formation of nodules

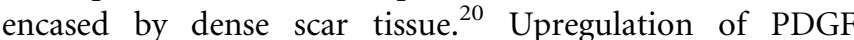
isoforms and their receptors appears to occur only in the inflammatory phase of liver injury.

Increased values of PDGF-B and PDGFR $\beta$ in liver injury and fibrogenesis are well documented in animal models and diseased human liver. ${ }^{4,21}$ Activated liver residential macrophages are primary sources of PDGF-B and other fibrotic cytokines. ${ }^{22,23}$ We demonstrated positive PDGFR $\beta$ staining in myofibroblasts that are the main source of extracellular matrix, along the centrilobular fibrotic septa, whereas PDGFB-positive immunostaining corresponded with the presence of inflammatory cells and ED2-positive Kupffer cells.

PDGF-D, another specific ligand of PDGFR $\beta^{24,25}$ upregulated simultaneously with PDGF-B, as previously reported in a BDL model. ${ }^{3}$ Immunostaining of PDGF-D was positive in bile duct epithelia and mesenchymal cells along fibrotic septa, in agreement with previous findings showing elevated expression of PDGF-D mRNA in culture-activated HSC. ${ }^{26}$

Besides upregulation of PDGFR $\beta$, PDGFR $\alpha$ was shown to increase in endothelial cells and hepatocytes outside the area of necrosteatosis. This phenomenon seems to be triggered by a reaction of hepatocyte survival compensatory response in toxin-induced hepatocellular damage. This upregulation of PDGFR $\alpha$ was accompanied by strong PDGF-A and PDGF-C reactivity upon $\mathrm{CCl}_{4}$ intoxication.

The positive immunostaining of PDGF-A observed in regenerative hepatocytes after $\mathrm{CCl}_{4}$ treatment was duly confirmed by immunoblot of isolated hepatocytes, corresponding well with previous findings indicating an abundant presence of PDGF-A mRNA in hepatocytes of injured human livers. ${ }^{21}$

PDGF-C staining was found in inflammatory areas along the fibrotic septa, confirming previous reporting that in response to lipopolysaccharide, IL-1 or TNF- $\alpha$, platelets immigrate into the liver in a fashion different from aggregation and enter into hepatocytes ${ }^{27}$ in which hepatic macrophages have a critical role. PDGF-C levels in platelet $\alpha$-granules showed higher expression than in other cell types ${ }^{28}$ explaining the significant increase of PDGF-C in our $\mathrm{CCl}_{4}$ model compared to the BDL model.

It was reported recently that overexpression of liver-specific PDGF-C, a ligand for PDGFR $\alpha$, resulted in liver fibrosis, steatosis and HCC in mice. ${ }^{29}$ In our experiment we found upregulation of PDGFR $\alpha$, PDGF-A and PDGF-C to correlate closely with the level of necrosteatotic liver damage (Supplementary Figure 8), but not to fibrosis that might be due to the limited 4-week-period of PDGF isoform and receptor expression. Chronic $\mathrm{CCl}_{4}$ administration has been shown to induce HCC in rodents, ${ }^{30}$ yet in our experiments we did not detect any hyperplasia or dysplasia within 12 weeks of $\mathrm{CCl}_{4}$ exposure (Supplementary Figure 6). HCC in human patients also revealed elevated PDGFR $\alpha$ levels compared to the adjacent normal livers, but any correlation between PDGFR $\alpha$ upregulation and liver fibrosis is considered coincidental only, but PDGFR $\beta$ protein was significantly expressed in fibrotic HCC livers. ${ }^{31}$ PDGFR $\alpha$ signaling therefore does not appear to promote liver fibrosis.

Despite continued $\mathrm{CCl}_{4}$ administration, the levels of all PDGF isoforms and their receptors returned to near normal at 8 and 12 weeks. This seems to indicate that PDGF has a pivotal role in the early stages of fibrogenesis through HSC and myofibroblast activation and proliferation, and subsequent extracellular matrix production leading to liver fibrosis. This might potentially explain why PDGF antagonists in liver fibrosis were only effective when applied in the early stages. ${ }^{32,33}$

We further found that the outcome of $\mathrm{CCl}_{4}$-induced liver fibrosis differs between individual rats (Supplementary Figure 4; Figure 5a). The degree of liver injury was previously believed to be proportional to the generation of the reactive metabolites of $\mathrm{CCl}_{4}$, but we now accept that the effects of biological responses to toxic injury, such as liver regeneration and tissue repair, determine the final toxic outcome. ${ }^{34}$ Tissue repair in $\mathrm{CCl}_{4}$ hepatotoxicity increases in a dose-dependent manner up to the threshold dose $(2 \mathrm{ml} / \mathrm{kg}) .{ }^{11}$ Low to moderate doses stimulate tissue repair, but doses beyond the threshold inhibit tissue repair resulting in accelerated progression of injury and culminating in organ failure and death. Moderate dosing $(1 \mathrm{ml} / \mathrm{kg})$ did result in acute liver damage as

Figure 4 Immunohistochemistry of PDGF receptors and isoforms in $\mathrm{CCl}_{4}$ rat livers. (a) In liver sections taken from $\mathrm{CCl}_{4}$-treated animals ( $+\mathrm{CCl}_{4}$, middle and right panels), PDGF-A-positive staining (brown color) was detected in bile duct epithelia (marked as B) and regenerative hepatocytes peripheral to the area of centrilobular hepatic necrosteatosis. PDGF-A was not detectable in control animals (- $\mathrm{CCl}_{4}$, left panel). A staining with a goat lgG served as negative control (not shown). Portal vein, portal arteria and bile duct epithelia are labeled by PV, PA, and B, respectively. (b) Immunohistochemistry showed positive staining of PDGFR $\alpha$ (brown color) in both perivascular fibroblasts, endothelial cells (E, middle panel) and regenerative hepatocytes (H, right panel) of cirrhotic livers. (c) Although PDGFR $\beta$ was not detectable in normal liver (left panel), a strong expression of PDGFR $\beta$ was noticeable in myofibroblasts along the fibrotic septa between the centrilobular bridging (brown color) in livers from animals that received $\mathrm{CCl}_{4}$ (right panel). (d) In liver sections taken from $\mathrm{CCl}_{4}$-treated rats, PDGF-B expression in APAAP immunostain (red color) was found in inflammatory cells corresponding to ED2-positive Kupffer cells (black arrow). Likewise, PDGF-C expression was found in inflammatory cells and further in hepatocytes around central veins. PDGF-D staining was found in bile duct epithelia (marked as B) and some myofibroblasts. The scale bar in each figure represents $100 \mu \mathrm{m}$. 


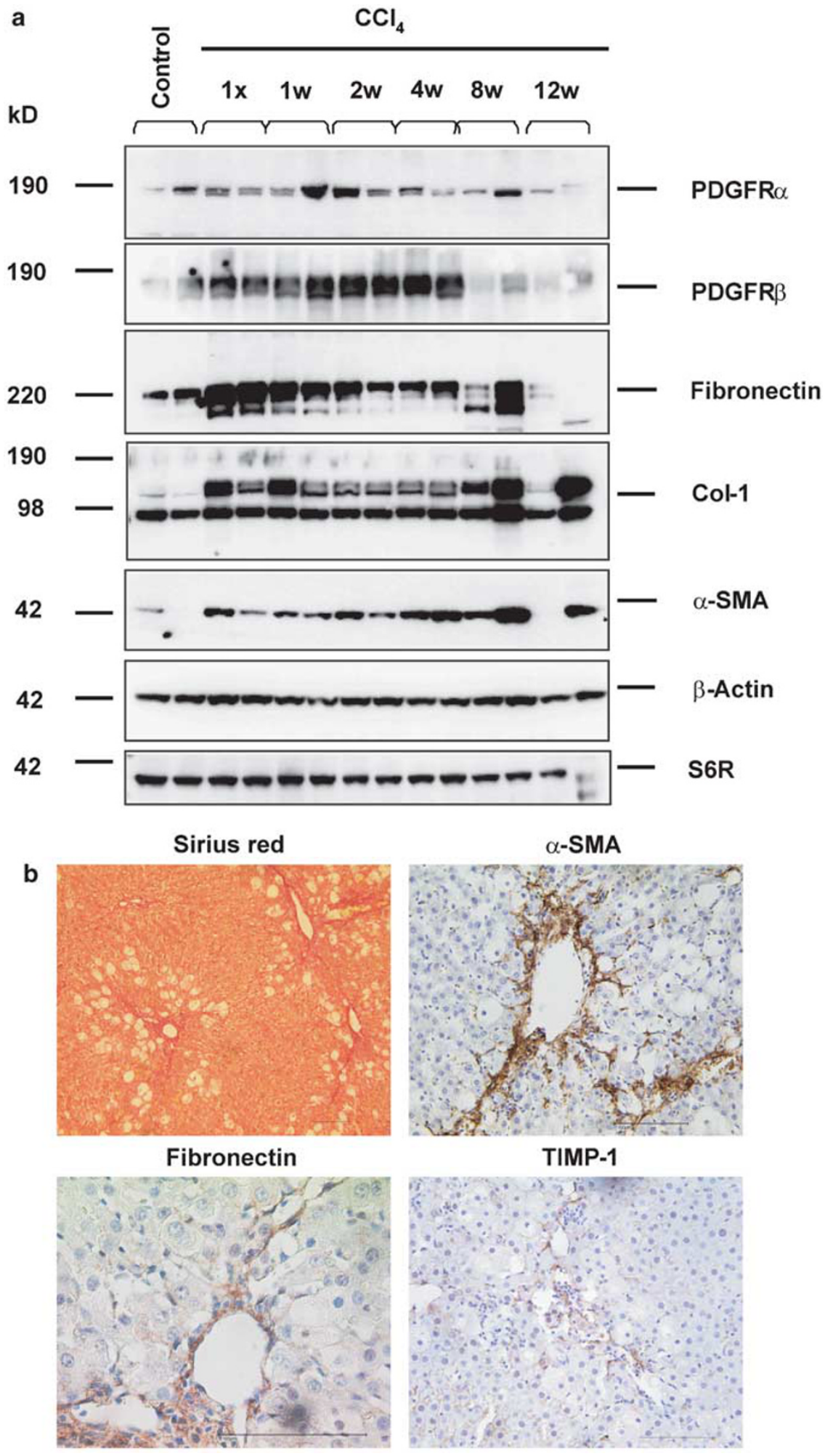

Figure 5 Fibrotic effects of chronic $\mathrm{CCl}_{4}$ administration. (a) Total liver protein extracts were prepared and analyzed for expression of PDGFR $\alpha$, PDGFR $\beta$, fibronectin, collagen type I (Col-I), $\alpha$-smooth muscle actin ( $\alpha$-SMA), $\beta$-actin and ribosomal protein S6 (S6R). The immunoblot revealed increased PDGFR $\alpha$ and PDGFR $\beta$ expression upon $\mathrm{CCl}_{4}$ administration that was sustained during the first 4 weeks after intoxication. The expression of fibronectin increased rapidly in the early stage, sustained for 8 weeks and declined thereafter. Expression of Col-I and $\alpha$-SMA increased during $\mathrm{CCl}_{4}$ administration. However, some animals with lesser degree of fibrosis (Supplementary Figure 5) showed lower contents of $\alpha$-SMA and Col-I at later stages (12 weeks). (b) Sirius red stain and immunohistochemical detection of $\alpha$-SMA (2-week $\mathrm{CCl}_{4}$ administration), fibronectin and TIMP-1 (1 week $\mathrm{CCl}_{4}$ ). All fibrogenic marker proteins were localized along the centrilobular fibrotic septa. The scale bar in each figure represents $100 \mu \mathrm{m}$. 

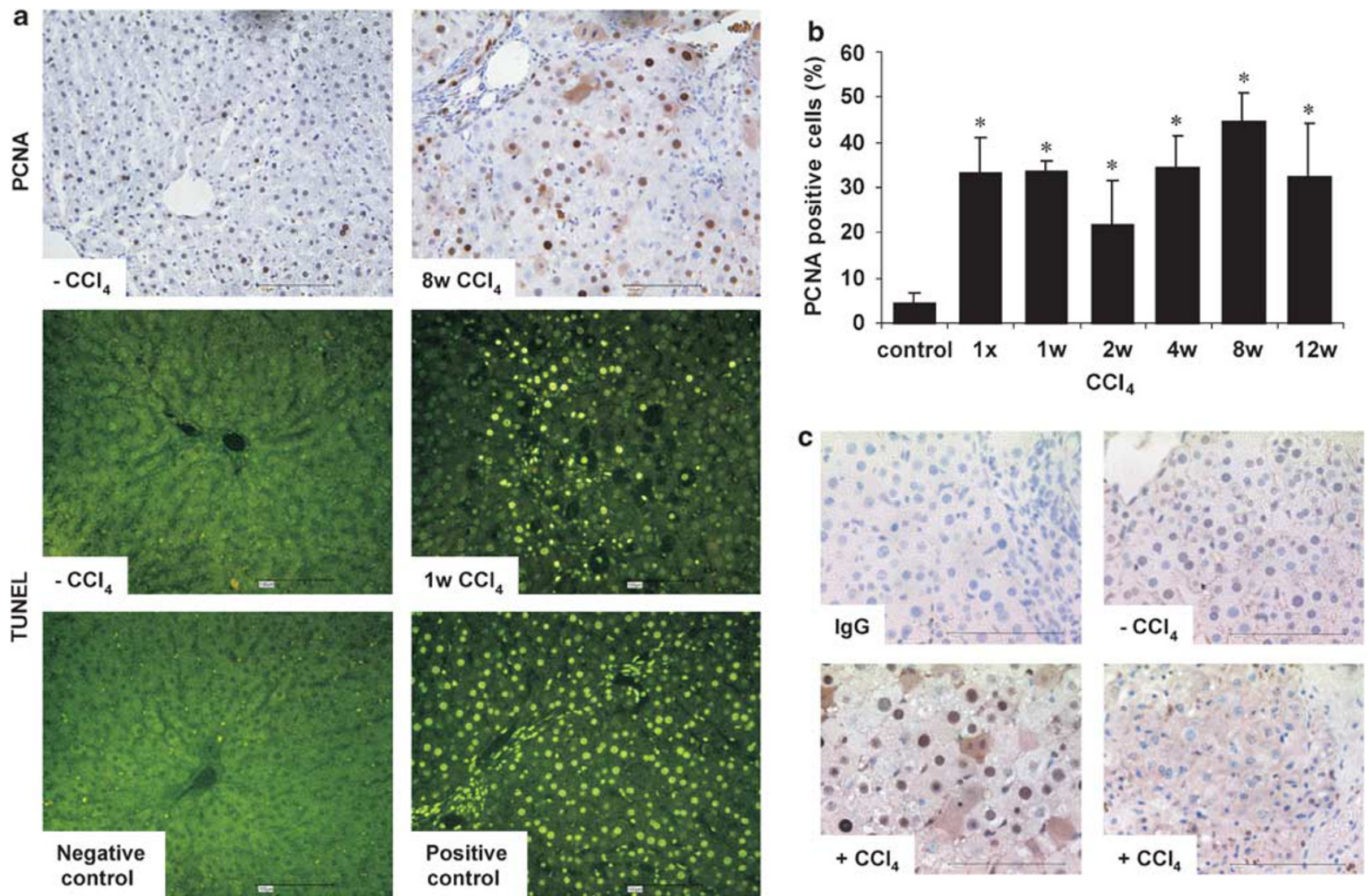

Figure 6 PCNA and TUNEL staining. (a) Serial staining for the proliferating cell nuclear antigen (PCNA, upper panel) and TUNEL staining (lower panels) was performed as outlined in 'Materials and methods'. Hepatocyte regeneration indicated by PCNA-positive staining (brown color) was found throughout the course of $\mathrm{CCl}_{4}$ application. Severe $\mathrm{CCl}_{4}$-induced acute hepatocellular damage was indicated by hepatocyte apoptosis at 1 week. For positive control staining, sections were incubated with DNase I before TUNEL reaction, whereas in the negative control TdT was omitted in the assay. (b) PCNA-positive cells were quantified at given time points, reflecting significantly increased hepatocyte regeneration throughout $\mathrm{CCl}_{4}$ application peaking at 8 weeks ( ${ }^{*} P<0.05$ ) as compared to non- $\mathrm{CCl}_{4}$-treated control rats. (c) Livers with low degrees of fibrosis showed very high levels of PCNA (lower left). In severe fibrotic or cirrhotic livers (lower right) by contrast, we detected only insignificant amounts of PCNA that was comparable to normal livers (upper right) (scale $\mathrm{bar}=100 \mu \mathrm{m})$.

indicated by the highest hepatocyte apoptosis at 1 week, followed by hepatocyte regeneration as evidenced by PCNA immunostaining peaking at 8 weeks. The time of onset of the tissue repair also determines the extent of hepatic injury, and the interindividual differences in magnitude in which individual susceptibility to toxic chemicals is involved.

Interestingly, despite a significant decline of PDGF isoforms at 8 weeks of continued $\mathrm{CCl}_{4}$ administration, hepatocyte regeneration (PCNA) reached its high. Liver regeneration involves multiple cellular processes and a complex interaction with cytokines and growth factors. $\mathrm{CCl}_{4}$ induces damage and necrosis of centrilobular hepatocytes and their subsequent removal by inflammatory cells. Liver tissue repair results from asynchronous replication and migration of periportal hepatocytes into the hepatic centrilobular region. ${ }^{35}$ Isolated Kupffer cells from $\mathrm{CCl}_{4}$-treated rats produce TNF- $\alpha$ and IL- $6,{ }^{16}$ that are important in the initiation of liver regeneration by stimulating $G_{0}-G_{1}$ transition. ${ }^{36,37}$ Expression of TNF- $\alpha$ was also downregulated after 6 weeks of $\mathrm{CCl}_{4}$ administration, ${ }^{19}$ in correlation with PDGF isoforms and receptors. Therefore, PDGF-A and PDGFR $\alpha$ expression in hepatocytes might be involved in the initiation phase of hepatocyte regeneration and prevention of hepatocyte apoptosis through Akt activation as evidenced by PDGFR $\alpha$ inhibition in hepatoma cells that led to diminution of tumor cell survival. ${ }^{31}$ Rather than PDGF, HGF and its receptor (c-MET) are considered to have a central role in the progression from the $G_{1}$ to $S$ phase. Other mitogens involved in the proliferative phase are TGF- $\alpha$, EGF, insulin (IGF-1) and norepinephrine. ${ }^{38,39}$

PDGF isoform signaling in primary cultured hepatocytes was evident in our analysis (Figure 1a). Moreover, cultured hepatocytes produce PDGF-A (Figure 2) and proliferate in vitro in response to this cytokine (Figure 1b). Likewise, PDGF-B, -C and -D induced significant BrdU incorporation, such in line with recent findings showing DNA synthesis to increase significantly in hepatocytes co-cultured with platelets through activation of both Akt and ERK1/2. 
The role of PDGF in liver damage is primarily directed toward mesenchymal cell proliferation and extracellular matrix production, rather than to hepatocyte regeneration. The outcome of chronic toxic liver injury also depends on the individual capacity for tissue regeneration as evidenced by PCNA staining. Upregulation of PDGF is directly associated with acute liver injury, inflammation and early fibrogenesis. The level of PDGF found in chronic liver injury is, however, only marginally above normal.

Supplementary Information accompanies the paper on the Laboratory Investigation website (http://www.laboratoryinvestigation.org)

\section{ACKNOWLEDGEMENT}

This work was supported by grants from the Deutsche Forschungsgemeinschaft (SFB-542, WE2554-4) and the Stiftung Pathobiochemie und Molekulare Diagnostik of the Deutsche Vereinte Gesellschaft für Klinische Chemie und Laboratoriumsmedizin e.V. (DGKL).

\section{DISCLOSURE/DUALITY OF INTEREST}

The authors declare that they have no competing interest relevant to this article.

1. Fredriksson L, Li H, Eriksson U. The PDGF family: four gene products form five dimeric isoforms. Cytokine Growth Factor Rev 2004;15: 197-204.

2. Pinzani M, Knauss TC, Pierce GF, et al. Mitogenic signals for plateletderived growth factor isoforms in liver fat-storing cells. Am J Physiol 1991;260:C485-C491.

3. Borkham-Kamphorst $\mathrm{E}$, van Roeyen $\mathrm{CR}$, Ostendorf $\mathrm{T}$, et al. Pro-fibrogenic potential of PDGF-D in liver fibrosis. J Hepatol 2007;46:1064-1074.

4. Wong L, Yamasaki G, Johnson RJ, et al. Induction of beta-plateletderived growth factor receptor in rat hepatic lipocytes during cellular activation in vivo and in culture. J Clin Invest 1994;94:1563-1569.

5. Pinzani M, Milani S, Grappone C, et al. Expression of platelet-derived growth factor in a model of acute liver injury. Hepatology 1994;19:701-707.

6. Weber LW, Boll M, Stampfl A. Hepatotoxicity and mechanism of action of haloalkanes: carbon tetrachloride as a toxicological model. Crit Rev Toxicol 2003;33:105-136.

7. Constandinou C, Henderson N, Iredale JP. Modeling liver fibrosis in rodents. Methods Mol Med 2005;117:2372-2350.

8. Borkham-Kamphorst E, Stoll D, Gressner AM, et al. Antisense strategy against PDGF B-chain proves effective in preventing experimental liver fibrogenesis. Biochem Biophys Res Commun 2004;32:413-423.

9. Seglen PO. Preparation of isolated rat liver cells. Methods Cell Biol 1976;13:29-83.

10. Papeleu P, Vanhaecke $T$, Henkens $T$, et al. Isolation of rat hepatocytes. Methods Mol Biol 2006;320:229-237.

11. Gressner OA, Lahme B, Demirci I, et al. Differential effects of TGF- $\beta$ on connective tissue growth factor (CTGF/CCN2) expression in hepatic stellate cells and hepatocytes. J Hepatol 2007;47:699-710.

12. Ishak K, Baptista A, Bianchi L, et al. Histological grading and staging of chronic hepatitis. J Hepatol 1995;22:696-699.

13. Goodman ZD. Grading and staging systems for inflammation and fibrosis in chronic liver diseases. J Hepatol 2007;47:598-607.

14. Jarnagin WR, Rockey DC, Koteliansky VE, et al. Expression of variant fibronectins in wound healing: cellular source and biological activity of the EIIIA segment in rat hepatic fibrogenesis. J Cell Biol 1994;127: 2037-2048.

15. Rao PS, Mangipudy RS, Mehendale HM. Tissue injury and repair as parallel and opposing responses to $\mathrm{CCl}_{4}$ hepatotoxicity: a novel doseresponse. Toxicology 1997;118:181-193.
16. Abdel-Aziz G, Lebeau G, Rescan PY, et al. Reversibility of hepatic fibrosis in experimentally induced cholestasis in rat. Am J Pathol 1990;137:1333-1342.

17. Swain MG, Tjandra K, Kanwar $S$, et al. Neutrophil adhesion is impaired in rat model of cholestasis. Gastroenterology 1995;109:923-932.

18. Armendariz-Borunda J, Seyer JM, Kang AH, et al. Regulation of TGF $\beta$ gene expression in rat liver intoxicated with carbon tetrachloride. FASEB J 1990;4:215-221.

19. Luckey SW, Petersen DR. Activation of Kupffer cells during the course of carbon tetrachloride-induced liver injury and fibrosis in rats. Exp Mol Pathol 2001;71:226-240.

20. Geerts A, Schellinck P, Bouwens $L$, et al. Cell population kinetics of Kupffer cells during the onset of fibrosis in rat liver by chronic carbon tetrachloride administration. J Hepatol 1988;6:50-56.

21. Pinzani M, Milani $S$, Herbst $H$, et al. Expression of platelet-derived growth factor and its receptors in normal human liver and during active hepatic fibrogenesis. Am J Pathol 1996;148:785-800.

22. Shimokado K, Raines EW, Madtes DK, et al. A significant part of macrophage-derived growth factor consists of at least two forms of PDGF. Cell 1985;43:277-286.

23. Friedman SL, Arthur MJ. Activation of cultured rat hepatic lipocytes by Kupffer cell conditioned medium. Direct enhancement of matrix synthesis and stimulation of cell proliferation via induction of plateletderived growth factor receptors. J Clin Invest 1989;84:1780-1785.

24. Bergsten E, Uutela M, Li X, et al. PDGF-D is a specific, protease-activated ligand for the PDGF beta-receptor. Nat Cell Biol 2001;3:512-516.

25. LaRochelle WJ, Jeffers M, McDonald WF, et al. PDGF-D, a new proteaseactivated growth factor. Nat Cell Biol 2001;3:517-521.

26. Breitkopf K, Roeyen C, Sawitza I, et al. Expression patterns of PDGF-A $-B,-C$ and $-D$ and the PDGF-receptors $\alpha$ and $\beta$ in activated rat hepatic stellate cells (HSC). Cytokine 2005;31:349-357.

27. Nakamura M, Shibazaki M, Nitta Y, et al. Translocation of platelets into Disse spaces and their entry into hepatocytes in response to lipopolysaccharides, interleukin-1 and tumour necrosis factor: the role of Kupffer cells. J Hepatol 1998;28:991-999.

28. Fang $L$, Yan $Y$, Komuves $L G$, et al. PDGF $C$ is a selective alpha plateletderived growth factor receptor agonist that is highly expressed in platelet alpha granules and vascular smooth muscle. Arterioscler Thromb Vasc Biol 2004:24:787-792.

29. Campbell JS, Hughes SD, Gilbertson DG, et al. Platelet-derived growth factor $\mathrm{C}$ induces liver fibrosis, steatosis, and hepatocellular carcinoma. Proc Natl Acad Sci USA 2005;102:3389-3394.

30. Frezza EE, Gerunda GE, Farinati $F$, et al. $\mathrm{CCl}_{4}$-induced liver cirrhosis and hepatocellular carcinoma in rats: relationship to plasma zinc, copper and estradiol levels. Hepatogastroenterology 1994;41:367-369.

31. Stock $P$, Monga $D$, Tan $X$, et al. Platelet-derived growth factor receptor- $\alpha$ : a novel therapeutic target in human hepatocellular cancer. Mol Cancer Ther 2007;6:1932-1941.

32. Borkham-Kamphorst E, Herrmann J, Stoll D, et al. Dominant-negative soluble PDGF-beta receptor inhibits hepatic stellate cell activation and attenuates liver fibrosis. Lab Invest 2004;84:766-777.

33. Neef $M$, Ledermann $M$, Saegesser $H$, et al. Oral imatinib treatment reduces early fibrogenesis but does not prevent progression in the long term. J Hepatol 2006;44:167-175.

34. Mehendale HM. Tissue repair: an important determinant of final outcome of toxicant-induced injury. Toxicol Pathol 2005;33: 41-51.

35. Lee VM, Cameron RG, Archer MC. Zonal location of compensatory hepatocyte proliferation following chemically induced hepatotoxicity in rats and humans. Toxicol Pathol 1998;26:621-627.

36. Fausto N. Liver regeneration. J Hepatol 2000;32:19-31.

37. Black D, Lyman S, Heider TR, et al. Molecular and cellular features of hepatic regeneration. J Surg Res 2004;117:306-315.

38. Michalopoulos GK, DeFrances M. Liver regeneration. Adv Biochem Eng Biotechnol 2005;93:101-134.

39. Fausto N, Campbell JS, Riehle KJ. Liver regeneration. Hepatology 2006;43:S45-S53.

40. Matsuo R, Ohkohchi N, Murata S, et al. Platelets strongly induce hepatocyte proliferation with IGF-1 and HGF in vitro. J Surg Res 2008;145:279-286. 